\title{
Discussion on the Role of Applied Mathematics in Higher Vocational Education
}

\author{
Jianlan Zhou \\ Nanjing Institute of Mechatronic Technology \\ Nanjing, China 211135
}

\begin{abstract}
Applied mathematics plays an important role in mathematics education, so we must attach great importance to the role of Applied Mathematics, and strengthen its role in mathematics education, so the quality and level of mathematics education can be improved significantly. This paper first expounds the role of applied mathematics in mathematics education, then put forward the strategy of consolidating applied mathematics in maths education, hoping play a positive role in enhancing the value of applied mathematics.
\end{abstract}

Keywords-applied mathematics; education; significance; strategy

\section{THE FUNCTION OF APPLIED MATHEMATICS IN MATHEMATICS EDUCATION}

Applied mathematics plays a very important role in all fields of social development and it is been widely recognized in each field. So we must actively explore the significance of applied mathematics in maths education.

\section{A. Applied Mhematics is Helpful to Improve the Students' Mathematics Accomplishment}

Mathematics education requires students to have a strong ability of thinking, otherwise it is difficult to adapt to some special problems in the process of learning. Applied mathematics can enable students to lay a solid foundation of mathematics learning to master more practical thinking methods and have a more comprehensive thinking ability. So students' thinking ability will be more complete to better enhance their comprehensive quality, which is conducive to the smooth development of mathematics education.

\section{B. Applied Mathematics is Helpful to Consolidate the Position of Mathematics Education in the Group Field}

Applied mathematics can provide more intelligence support for computer and scientific research, making these areas of development have more solid guarantee. Therefore, in a sense, applied mathematics can effectively consolidate the status of ideological education, making mathematics education really become the basic subject of research in the field to play a positive role in promoting the development of other related fields.

\section{Applied Mathematics is Helpful to Stimulate Students Interests}

The value of applied mathematics has been reflected in many related fields. Therefore, after identifying it, students certainly can foresee the scope for applied mathematics. In this way, students will be more active in learning maths and stimulate greater interests, laying a good foreshadowing for future employment, so that mathematics education goal realization go more smoothly.

\section{Applied Mathematics is Helpful to Sucessfully Change into Applied Thinking}

As people grow older and with the continuous improvement of the difficulty of knowledge, students' thinking needs the development from imaginal thinking to applicational thinking. However, the transition from imaginal thinking to applicational thinking must be based on image thinking ability. Otherwise, if students can not accept it, it is difficult to achieve the good transition to applicational thinking, which eventually leads to half knowledge of maths to students. Therefore, applied mathematics not only becomes the key to cultivate and strengthen students' imaigal thinking, but cultivates students' thinking ability in a good transition.

\section{The STRATEGy OF CONSOLIDATING APPLIED EDUCATION IN MATHS EDUCATION}

Applied mathematics plays a very practical role for learning. Therefore, we must take it seriously in maths education status to make it recognized by students and highlight the role by effective strategies.

\section{A. Clarify the Relationship between the Applied Mathematics Education and Students' Quality and Demonstrate the Value of Maths Education}

Maths education should take learning as the channel and teachers should increase their own educational knowledge to put long vision of applied mathematics education. This requires that teachers should learn to recognize the existing models of mathematics education and the employment of students, to analyze the deep relationship between learning of applied mathematics and their future employment, so that it is for students to better carry out applied mathematics education, to ensure the realization of the expected goals of education, to stable expectable education outcomes, to show the desired 
effects of applied mathematics. It not only gets applied mathematics knowledge of students to improve the students' thinking ability, but effectively demonstrates the value of applied mathematics to consolidate the status of it.

\section{B. Teachers Should Change Their Ideological Consciousness to Pay Attention to the Cultivation of Students' Ability to Apply Mathematics}

First of all, the current education situation is also formed under the situation of full respect for the law of social development. Therefore, social development situation calls for education mode which adapted to them and education results. This requires teachers to renew ideas, paying attention to existence of applied mathematics-realistic meaning, satisfying various requirements of applied mathematics for the social development. Fully understanding the background of mathematics education can better develop the applied maths education, establish the awareness, and cultivate the ability to lay a solid foundation.

Secondly, teachers should learn to cultivate students' thinking ability in the course of education. Taking thinking ability as the breakthrough point make students have a clear cognition of development prospects of applied mathematics so as to encourage students to develop good thinking ability , making maths educating more in line with the situation of social development and conforming to the intrinsic need of education situation. Eventually, good thinking ability can be brought into full play in applied mathematics, promoting the continuous development of applied maths.

\section{Students Cooperate with Teachers' Teaching Requirements to Provide the Condition for Applied Mathematics}

First, in the process of promoting applied mathematics education, it is not enough to rely solely on teachers to change their ideas, it also needs the active participation of students. As the recipient of maths knowledge and the culturist of maths ability, the most critical factor is the ideas and behaviors of students. Therefore, teachers should let students make the transition from the ideology, encouraging them to get a clear understanding of the existing educational situation, cultivating their ability of applied mathematics in a timely manner, so as to improve the status of mathematics education foreshadowed.

Under the guidance of teachers, students make ideological transformation and this change is reflected in the behavior to actively cooperate with the teacher's mathematics education activities, so that teachers and students reach a consensus in thought and consistent form in behavior, through coordination and cooperation of education, making the goal of education is more fit the inherent requirement.

\section{Effectively Keep the Students' Learning Enthusiasm and Form a Good Learning State}

Students' enthusiasm for learning is going to promote the power of applied mathematics. Teachers should have a good communication with students to make them not only have a passion for applied maths to deeply understand the significance of applied maths, but clear the significance of applied maths in future employment to transform passion to motive for learning and maintain it for a long time.

Of course, applied mathematics education needs to be carried out in an atmosphere of peace and harmony, otherwise, if lacking of a good teaching atmosphere, students do not mind listening to teachers and teachers are no mood to be lectured, directly affecting the cultivation of applied mathematics. Therefore, equal and active classroom teaching has appealed and better actively mobilized the students to provide a good platform for the development of the application of mathematics education.

\section{CONCLUSION}

Applied mathematics education is related to the students' thinking ability and process of mathematics education, so its level is particularly important. We have to make efforts based on the reality and capture scientific and rational viewpoints to establish the new environment of applied mathematics education, improving the level of applied maths education through the scientific and reasonable education strategy to further enhance the overall level of mathematics education.

\section{REFERENCES}

[1] Qiu Benhua, Yao Qinghua, The Role of College Mathematics in Various Fields[J], Chinese Science and Techonology, 2010 (22): 133133.

[2] Li Baoping, Discussion on the Application of Mathematics in Economic Field $[J]$, The Science Dducation Article Collects (the next ten-day period ), 2011 (6): 30-30. 